\title{
Screening strategies for colorectal cancer: A systematic review of the evidence
}

Robin S McLeod MD FRCSC FACS, and members of the Canadian Task Force on Preventive Health Care

RS McLeod. Screening strategies for colorectal cancer: A systematic review of the evidence. Can J Gastroenterol $2001 ; 15(10): 647-660$.

BACKGROUND: Colorectal cancer is the third most common cancer in Canada. It is well recognized that there are improved survival rates if the disease is treated in its early stages, and indeed this may be a preventable disease. This paper systematically reviews the effectiveness of specific screening techniques for colorectal cancer in asymptomatic individuals at normal or above average risk.

METHODS: MEDLINE was searched for articles published between January 1966 and January 2001 by using the MESH terms 'screening' and 'colorectal neoplasia'. The reference sections of review articles published before January 2001 were checked, and content experts were surveyed. The evidence was evaluated using the standardized methodology of the Canadian Task Force on Preventive Health Care.

RESULTS AND DISCUSSION: For individuals at normal risk, there is evidence to support the use of annual or biennial fecal occult blood testing and flexible sigmoidoscopy for asymptomatic individuals over age 50 years. The evidence regarding whether only one or both of fecal occult blood testing and sigmoidoscopy should be performed is unclear, as is the evidence regarding the use of colonoscopy as an initial screen. For individuals at above average risk, the evidence supports either genetic testing or flexible sigmoidoscopy of individuals at risk in familial adenomatous polyposis kindreds, and screening with colonoscopy of patients in kindreds with hereditary nonpolyposis colon cancer. The evidence regarding colonoscopy for individuals who have a family history of colorectal polyps or cancer but do not fit the criteria for hereditary nonpolyposis colon cancer is unclear. Development of better risk stratification for screening is a high research priority, and further research, including randomized, controlled trials, into the effectiveness and feasibility of other screening modalities is necessary.

Key Words: Colorectal cancer; Screening; Systematic review pour le résumé, voir page suivante

University of Toronto, Samuel Lunenfeld Research Institute, Mount Sinai Hospital, Toronto, Ontario with the Canadian Task Force on Preventive Health Care, St Joseph's Health Centre - Parkwood Site, London, Ontario

Correspondence: Dr Robin S McLeod, Room 449, Mount Sinai Hospital, 600 University Avenue, Toronto, Ontario M5G 1 X5. Telephone 416-586-8534, fax 416-586-8644, e-mail rmcleod@mtsinai.on.ca

The Canadian Task Force on Preventive Health Care practice recommendations associated with this systematic review are available by contacting the Canadian Task Force office: Telephone 519-685-4292 ext 42327, fax 519-685-4016, email ctf@ctfphc.org

Received for publication April 16, 2001. Accepted August 16, 2001 


\section{Stratégies de dépistage du cancer colorectal : Revue systématique des preuves}

HISTORIQUE : Le cancer colorectal est le troisième cancer le plus fréquent au Canada. On sait que les taux de survie sont meilleurs si la maladie est traitée au début et il serait même possible de prévenir la maladie. Cet article passe systématiquement en revue l'efficacité des techniques de dépistage spécifiques du cancer colorectal chez des sujets asymptomatiques exposés à un risque normal ou au-dessus de la moyenne. MÉTHODES : On a interrogé le réseau MEDLINE pour recenser les articles publiés entre janvier 1966 et janvier 2001 au moyen des termes MESH "screening" et "colorectal neoplasia". Les bibliographies des articles passés en revue publiés avant janvier 2001 ont été vérifiées et des experts en la matière ont été interrogés. Les preuves ont été évaluées à l'aide d'une méthodologie standardisée par le Groupe d'étude canadien sur les soins de santé préventifs.

RÉSULTATS ET DISCUSSION : Pour les personnes exposées à un risque normal, il y aurait lieu de procéder à des tests de dépistage sang occulte dans les selles tous les ans ou tous les deux ans et à une sigmoïdoscopie chez les sujets de plus de 50 ans asymptomatiques. Il n'a pas encore été prouvé qu'il faille procéder à l'une des deux ou aux deux interventions (recherche de sang dans les selles et sigmoïdoscopie) tout comme on ignore s'il faut procéder à une colonoscopie lors du dépistage initial. Pour les personnes exposées à un risque au-dessus de la normale, les preuves préconisent des tests génétiques ou la sigmoïdoscopie pour les sujets à risque ayant des antécédents familiaux de polypose adénomateuse et le dépistage par colonoscopie chez les patients ayant des antécédents familiaux de cancer du côlon héréditaire sans polypose. Les preuves quant au bien-fondé de la colonoscopie chez les sujets qui avaient des antécédents familiaux de polypes ou de cancers colorectaux sans correspondre aux critères du cancer du côlon héréditaire sans polypose ne sont pas concluantes. La mise au point d'une stratification plus précise du risque pour le dépistage est une importante priorité de recherche et d'autres travaux, notamment des essais cliniques randomisés contrôlés, s'imposent pour mesurer l'efficacité et l'applicabilité d'autres modalités de dépistage.
$\mathrm{C}$ olorectal cancer is a leading cause of death in the Western world. In Canada, colorectal cancer is the third most common cancer, accounting for more than $12 \%$ of cases of cancer in both sexes. It was estimated that there would be 17,000 new cases of and 6500 deaths from colorectal cancer in Canada in 2000 (1). These rates, particularly among men, are among the highest in the world.

It is well recognized that survival rates are improved if the disease is treated in its early stages (2). Furthermore, with advances in endoscopic techniques, which may be used for both detection and removal of precursor lesions, colorectal cancer is theoretically a preventable disease (3). As a result, there is much interest in the various screening manoeuvres available for the early detection of both adenomas and carcinomas. In the past few years, several trials assessing the effectiveness of screening for colorectal cancer have been completed.

This systematic review examines the effectiveness of specific screening techniques for colorectal cancer in asymptomatic patients and updates the 1994 review by the Canadian Task Force on Preventive Health Care (Appendix 1) (4).

The most common protocol for screening for colorectal cancer in average risk individuals is a multiphase manoeuvre, with fecal occult blood testing (FOBT) initially followed by colonoscopy or flexible sigmoidoscopy and barium enema in patients with a positive test result for the presence of occult blood. The Hemoccult test (Beckman Coulter, USA) detects the peroxidase-like activity of hemoglobin (5). The HemoQuant (HemeLab Inc, USA) test detects the porphyrin-like moiety of hemoglobin (6). Immunochemical tests for fecal hemoglobin have been developed based on various techniques, including radial immunodiffusion, latex hemagglutination, ELISA and monoclonal antibodies against hemoglobin $(7,8)$. Of these, the HemeSelect (SmithKline Diagnostics, USA) test has been used most extensively.

An alternative to multiphase screening is screening with sigmoidoscopy alone or colonoscopy for average risk indi-
TABLE 1

Estimated rates of colorectal cancer in Canada by age (2000)

\begin{tabular}{lccc}
\hline Age (years) & $\begin{array}{c}\text { Number of } \\
\text { cases }\end{array}$ & $\begin{array}{c}\text { Population } \\
(\times \mathbf{1 0 0 0})\end{array}$ & Rate/1000 \\
\hline $20-29$ & 40 & 4249 & 0.01 \\
$30-39$ & 250 & 5122 & 0.05 \\
$40-49$ & 940 & 4995 & 0.18 \\
$50-59$ & 2400 & 3653 & 0.66 \\
$60-69$ & 4200 & 2417 & 1.74 \\
$70-79$ & 5400 & 1832 & 2.95 \\
$80-89$ & 3700 & 960 & 3.85 \\
\hline
\end{tabular}

viduals (9). In high risk groups, uniphase screening with colonoscopy has been recommended. Surgical resection remains the standard therapy for colorectal cancer, but adjuvant therapy with radiation and chemotherapy has also been shown to improve the outcome in some patients (10).

The etiology of colorectal cancer is unknown, but most cancers arise from benign adenomas following the 'polypcancer sequence' (11). Most cancers occur sporadically, but it is estimated that up to $15 \%$ of cancers may have a genetic basis (12). Thus, people with familial adenomatous polyposis (FAP), which accounts for $1 \%$ of all colorectal cancers, and those with hereditary nonpolyposis colon cancer (HNPCC), which may account for another $5 \%$ of colorectal cancers, are at high risk for the development of colorectal cancer. Age is a significant risk factor. Less than $2 \%$ of cases occur in people younger than 40 years of age. The risk of colorectal cancer in a patient 50 years of age is 18 to 20 times that in a patient 30 years of age, and the risk doubles about every seven years thereafter (13). In Canada, in 2000, it was estimated that there would be 940 cases of colorectal cancer in individuals between 40 and 49 years of age compared with 2400 individuals between 50 and 59 years of age. The risk increased at age 80 years (1) (Table 1). 
TABLE 2

Results of trials of multiphase screening for colorectal cancer (CRC) with the Hemoccult test as the first stage

\begin{tabular}{|c|c|c|c|c|}
\hline \multirow[b]{2}{*}{ Study } & \multirow[b]{2}{*}{ Mandel et al (17-20) } & \multicolumn{2}{|c|}{ Author (reference) } & \multirow[b]{2}{*}{ Kewenter et al $(26,27)$} \\
\hline & & Kronborg et al $(21,23)$ & Hardcastle et al $(24,25)$ & \\
\hline Level of evidence & I & 1 & I & I \\
\hline Age of subjects (years) & $50-80$ & $45-74$ & $50-74$ & $60-64$ \\
\hline Number of subjects in screen group & 31,157 & 30,967 & 76,466 & 31,144 \\
\hline Number of subjects in control group & 15,394 & 30,966 & 76,384 & 34,164 \\
\hline Patients who were compliant (\%) & $75-78$ & 67 & 59 & 66 \\
\hline Sensitivity of test (\%) & $\begin{array}{l}49.5 \text { (annual screen) } \\
38.3 \text { (biennial screen) }\end{array}$ & 48 & 48 & 79 \\
\hline Number of cancers (rate/10,000) & $\begin{array}{c}\text { Annual screen } 323(207) \\
\text { Biennial screen } 323(207) \\
\text { Control } 356(231)\end{array}$ & $\begin{array}{l}\text { Screen } 893(117) \\
\text { Control } 856(112)\end{array}$ & $\begin{array}{l}\text { Screen } 371(108) \\
\text { Control } 379(111)\end{array}$ & $\begin{array}{l}\text { Screen } 481 \text { (155) } \\
\text { Control } 483(156)\end{array}$ \\
\hline Positive predictive value (\%) & 2.2 & $10.2-17.0$ & 9.9-11.9 & $4.6-5.0$ \\
\hline Follow-up (years) & 13 & 10 & Median 7.8 & Median 8.3 \\
\hline $\begin{array}{l}\text { CRC deaths at latest follow-up, } \\
\mathrm{n}(\text { rate/10,000) }\end{array}$ & $\begin{array}{l}\text { Annual screen } 82(53) \\
\text { Biennial screen } 117(75) \\
\text { Control } 121(79)\end{array}$ & $\begin{array}{l}\text { Screen } 360(47) \\
\text { Control } 420(55)\end{array}$ & $\begin{array}{l}\text { Screen } 121(35) \\
\text { Control } 138(40)\end{array}$ & $\begin{array}{l}\text { Screen } 205(66) \\
\text { Control } 249(80)\end{array}$ \\
\hline $\begin{array}{l}\text { RR of CRC death with screening } \\
(95 \% \mathrm{Cl})\end{array}$ & $\begin{array}{c}\text { Annual screen } 0.67 \\
(0.51 \text { to } 0.89) \\
\text { Biennial screen } 0.95 \\
\text { (0.74 to } 1.23) \\
\text { Total } 0.81 \\
(0.65 \text { to } 1.02)\end{array}$ & $0.86(0.74$ to 0.99$)$ & 0.88 (0.69 to 1.12$)$ & 0.82 (0.68 to 0.99$)$ \\
\hline
\end{tabular}

RR Rate ratio

People with ulcerative colitis (14), and those who have had previous polyps or cancers are at increased risk for the development of colorectal cancer. These individuals have been excluded from this review because the management of those with identifiable disease is not generally part of the scope of a Canadian Task Force review.

\section{OBJECTIVES}

The effectiveness of colorectal cancer screening in normal risk patients was reviewed for multiphase screening with the Hemoccult test as first phase, multiphase screening with sigmoidoscopy and uniphase screening with colonoscopy. For patients with above average risk, the specific screening manoeuvres reviewed were flexible sigmoidoscopy and genetic testing for those with FAP, colonoscopy for those with HNPCC, and colonoscopy for patients with a family history (first-degree relative[s]) of polyps or colorectal cancer. The outcomes of interest were rates of cancer detection, deaths from cancer, compliance, feasibility and accuracy of each manoeuvre. The highest value was assigned to manoeuvres that lowered the rate of death from cancer and had a low rate of false-positive results, and acceptable cost and compliance.

\section{METHODS}

MEDLINE was searched for English language articles assessing screening for colorectal cancer published between January 1966 and January 2001, with the use of the MESH terms 'screening' and 'colorectal neoplasia'. Review articles published between these dates were retrieved, and their reference sections were used to cross-reference the MEDLINE search. Content experts were canvassed to ensure that no relevant articles were missed. Articles concerning Hemoccult testing or flexible sigmoidoscopy as the first step in a multiphase secondary prevention strategy or colonoscopy as a single-phase secondary prevention strategy in both asymptomatic and high-risk groups were included. Screening with digital rectal examination and double-contrast barium enema was not considered because of the lack of direct evidence.

The evidence was systematically reviewed using the methodology of the Canadian Task Force on Preventive Health Care. The Task Force of expert clinician/methodologists from a variety of medical specialties used a standardized evidence-based method for evaluating the effectiveness of preventive interventions. Cost effectiveness was not directly assessed. The full methodology is described by Woolf et al (15) and summarized in Appendix 2.

\section{RESULTS}

Screening average risk individuals - Screening with the Hemoccult test: Four large randomized, controlled trials (RCTs) have assessed the value of screening with the Hemoccult test (16-27). Death rates were derived from the most recent report from each trial (Table 2). Sensitivity and specificity data were derived from the raw data. They report the accuracy of the screening program for each patient rather than of each Hemoccult test performed on one patient, as has been reported in some studies. 
The University of Minnesota Colon Cancer Control Study began accruing subjects in 1975 (16-20). The 46,551 participants, who were between 50 and 80 years of age, were recruited from the American Cancer Society and fraternal, veteran and employee groups in Minnesota. They were randomly assigned to annual or biennial screening with the Hemoccult test or a control group and followed for 13 years. A high sensitivity of the Hemoccult test ( $88 \%$ to $92 \%$ ) for detecting cancer, a high compliance rate $(86 \%)$ and a cancer detection rate of 0.002 were originally reported. The high reported sensitivity may be a result of the method adopted for assessing sensitivity. They defined an interval cancer as one diagnosed within 12 months following a negative Hemoccult test. However, if the sensitivity of the test is determined from the number of carcinomas detected through screening divided by the total number of carcinomas, as was the definition used in the other trials, then after 13 years, the sensitivity for the group screened annually is $49.5 \%$ and for the group screened biennially $38.3 \%$. There were no differences in overall death rates among the three groups. However, the death rate from colorectal cancer was statistically significantly lower in the group screened annually (82 deaths) than in the control group (121 deaths) (rate ratio $[R R]=0.67 ; 95 \%$ CI 0.51 to 0.89 ). Initially, in the group screened biennially, the death rate due to colorectal cancer was lower (117 deaths) but not significantly so $(\mathrm{RR}=0.95 ; 95 \% \mathrm{CI} 0.74$ to 1.23$)$. Thus, the cumulative mortality was 5.88 per 1000 (95\% CI 4.61 to 7.15 ) in those who were screened annually, 8.33 per 1000 (95\% CI 6.82 to 9.84) in those who were screened biennially and 8.83 per 1000 (95\% CI 7.76 to 10.40 ) in the control group. However, in an updated report with 18 years of follow-up, a significant reduction in colorectal cancer deaths in the group screened biennially was reported (177 deaths in the biennially screened group compared with 144 deaths in the control group; RR 0.79; 95\% CI 0.62 to 0.97). As well, for those in the annually screened group, the RR at 18 years was 0.67 (95\% CI 0.51 to 0.83) (20). Thus, this represents a cumulative benefit of annual screening of 2.95 deaths averted per 1000 people and for biennial screening 0.5 deaths averted per 1000 people over the 13 years.

In this trial, the rate of positive slides was $9.8 \%$ when they were rehydrated. As a result, $38 \%$ (5917) of those in the group screened annually and 28\% (4365) of those in the group screened biennially had colonoscopic examinations to detect 646 cases of cancer. There were 15 major complications of the 12,246 colonoscopies performed at the university $(0.1 \%$ complication rate), including four perforations requiring surgery and 11 serious bleeds, of which three required surgery. There were no deaths.

A second population-based RCT conducted in Funen, Denmark, involved 61,933 people 45 to 75 years of age (2123). Patients in the screened group underwent the Hemoccult test at the outset of the study and biennially thereafter for 10 years. In the screened group, 481 cancers were detected compared with 483 in the control group. Of those in the screened group, 120 carcinomas were detected with screening, and 148 were interval cancers. Therefore, the sensitivity of the test for detecting cancer was $45 \%$. Overall, the tumours were at earlier stages in the screened group; significantly more subjects in the screened group had local $(10 \%$ versus $5 \%, \mathrm{P}<0.01)$ and curative surgery $(69 \%$ versus $59 \%, \mathrm{P}<0.01)$ for their cancers. In addition, adenomas larger than $10 \mathrm{~mm}$ were detected in 413 subjects in the screened group compared with 173 in the control group. As in the University of Minnesota study, overall mortality was not different between the two groups. However, there were 205 deaths due to colorectal cancer in the screened group, and 249 deaths due to colorectal cancer in the control group after 10 years, representing an $18 \% \mathrm{RR}(\mathrm{RR}=0.82$; 95\% CI 0.68 to 0.99). Unlike the University of Minnesota study, the Hemoccult slides were not rehydrated, and overall only $4.3 \%$ of screened subjects had a colonoscopic examination at some time during the study. This may be the reason for the lower risk reduction in the screened group but also means that the financial costs of the program were less. The complication rate associated with colonoscopy was not reported.

A population-based RCT conducted in the Nottingham area of the United Kingdom examined screening with the Hemoccult test at study entry and every two years thereafter $(24,25)$. Randomization was by household rather than by individual. Of the 75,253 individuals randomly assigned to screening, only 44,838 (59.6\%) completed at least one screening. In this study, slides were not rehydrated. For the initial test, subjects were not asked to restrict their diets. If the slides were positive, the subject was asked to repeat the test after being on a restricted diet. The sensitivity of the test was similar to that reported in the previous trials, with 236 of 485 (48.6\%) cancers detected by screening and 249 in the interval between screening. After a median follow-up of 7.8 years, there were 360 deaths due to colorectal cancer in the screened group compared with 420 deaths due to colorectal cancer in the control group, representing a statistically significant risk reduction of $15 \%(\mathrm{RR}=0.85 ; 95 \% \mathrm{CI}$ 0.74 to 0.98 ). In this study, as in the Danish study, only $4.0 \%$ of subjects underwent one or more colonoscopic examinations during the study. Possibly because of the low compliance rate, almost half of the cancers in the screened group were detected in nonresponders (ie, those who were not screened despite being randomly assigned to screening). Overall, only one-quarter $(n=236)$ of the 856 cancers in the screened group were actually detected by Hemoccult testing. It is also interesting to note that $74 \%$ of the screendetected cancers were in the rectum or sigmoid, which might have implications in considering a program of combined flexible sigmoidoscopy and FOBT, which has been suggested. In addition to the colorectal cancers, $1001 \mathrm{sub}$ jects in the screened group were found to have adenomas, of whom 267 had adenomas larger than $2 \mathrm{~cm}$ in diameter. In comparison, 370 subjects had adenomas in the control group, with 100 of them having polyps greater than $2 \mathrm{~cm}$ in size.

The fourth RCT was a population-based study started in 1982 in Goteberg, Sweden involving 68,308 subjects 
between 60 and 64 years of age $(26,27)$. Subjects in the screened group were offered Hemoccult testing at the start of the trial and then 16 to 24 months later. Subjects were asked to follow a restricted diet before the tests. Furthermore, to decrease the false-positive rate, subjects with a positive test were retested before undergoing followup examinations. Those with a positive second test were worked up with proctoscopy, flexible sigmoidoscopy and double-contrast barium enema. Colonoscopy was not performed initially. Overall, 3.8\% underwent workup after the first screen and $5.1 \%$ after the second screen. In this study, the sensitivity for the test was 79\% (81 of 102 cancers). Mortality data have not been published in a primary report, but mortality data were supplied so that a meta-analysis could be performed (28). To date, there have been 121 deaths in the screened group compared with 138 in the control group, representing a $12 \%$ risk reduction, which is not statistically significant.

Towler and colleagues (28) published a systematic review including the above-mentioned trials plus two nonrandomized studies. The first nonrandomized trial was performed at Memorial Sloan Kettering, New York, New York, to assess the additional benefit of Hemoccult testing in patients already being offered sigmoidoscopy (29-31). The second is a study from France that still has not reported mortality rates and, therefore, was not included in this analysis (32). The meta-analysis included over 330,000 individuals from the RCT and another 113,000 from the nonrandomized studies. The results from both biennial and annual screening from the four trials were combined and, using a random effects model, it was determined that there was a $16 \%$ risk reduction in mortality from colorectal cancer $(\mathrm{RR}=0.84 ; 95 \% \mathrm{CI} 0.77$ to 0.93$)$. The overall relative reduction in mortality was $23 \%$ for those who were compliant $(\mathrm{RR}=0.77 ; 95 \% \mathrm{CI} 0.57$ to 0.89$)$. They also estimated that, if 10,000 people were offered screening, 8.5 (95\% CI 3.6 to 13.5 ) deaths from colorectal cancer would be prevented over 10 years. The number needed to screen over 10 years to prevent one death would be 1173. As well, there is evidence from the University of Minnesota Trial that the detection and removal of adenomas decrease the incidence of colorectal cancer in the screened population. At 18 years, the cumulative incidence ratios for colorectal cancer in the screened groups compared with the control group were 0.80 (95\% CI 0.70 to 0.90 ) and 0.83 (95\% CI 0.73 to 0.94) for the groups screened annually and biennially, respectively. Thus, as follow-up continues, it is likely that a further decrease in cancer-related mortality will be realized.

In summary, there is evidence from four RCTs that FOBT with Hemoccult results in a significant decrease in mortality from colorectal cancer, but not in overall mortality. The RR reduction is in the order of $15 \%$; in absolute terms, approximately 8.5 deaths from colorectal cancer would be averted if 10,000 people were screened over 10 years (28). The RR reduction in mortality rates is fairly constant, but the colorectal cancer detection rate is higher in older individuals. Thus, if screening were to begin at a later age, the proportion of lives saved compared with those screened might be greater. The RR reduction may also vary depending on whether the test is performed annually or biennially, and whether the slides are rehydrated. In the University of Minnesota trial, in the group screened annually and where the slides were rehydrated, the RR reduction was considerably greater $(33 \%$ risk reduction compared with approximately $15 \%$ risk reduction in the other three trials). On the other hand, the positivity rate was highest in this group (9.8\%), and 38\% of subjects had a colonoscopy compared with approximately $4 \%$ of the screened subjects in the other trials. This has significant implications for the cost of a screening program. Significant adverse events, however, occurred in $0.1 \%$ of individuals having colonoscopy in the University of Minnesota trial (17).

While the trials have shown a significant reduction in colorectal cancer mortality with screening for fecal occult blood, there remain concerns about the sensitivity of Hemoccult testing and its value as a screening test. Overall, the sensitivity of the test for detecting colorectal cancer was approximately $50 \%$ in three of the trials. Lang and Ransohoff (34) analyzed the data from the University of Minnesota trial and suggested that one-third to one-half of the mortality reduction was the result of chance selection, simply due to colonoscopies being performed in a large proportion of subjects. They questioned the need for FOBT and whether colonoscopic examinations alone should be performed. Finally, none of these studies addressed the psychological issues of screening nor the acceptability of screening on a community basis (35). The Nottingham trial perhaps provided the best data from the RCTs on the acceptance of mass screening, and almost $60 \%$ of invited individuals participated (25). However, other studies have shown much lower compliance rates both for the initial testing and for the follow-up investigations (36).

Screening with sigmoidoscopy: The Kaiser Multiphasic Evaluation Study was an RCT involving members of a medical care program 35 to 54 years of age who were encouraged (study group) or not actively encouraged (control group) to schedule a multiphase health checkup that included a sigmoidoscopic examination (37). At each checkup, patients in both groups were offered sigmoidoscopic examination. Thus, this study determined whether compliance was improved with encouragement rather than the effectiveness of sigmoidoscopic examination as a screening procedure for colorectal cancer.

The investigators re-analyzed the data from these groups (38). They retrospectively reviewed the charts of patients who had died of colorectal cancer and compared them with the charts of matched control subjects to determine the proportion of patients in each group who had been examined with rigid sigmoidoscopy in the preceding 10 years. Of the patients who had died of colorectal cancer, $8.8 \%$ had undergone sigmoidoscopy within the preceding 10 years, compared with $24.2 \%$ of the control patients. After adjustment, the odds ratio was 0.41 (95\% CI 0.25 to 0.69 ). Another group of individuals with fatal colon cancer above 
the reach of the sigmoidoscope was compared with a control group. There was no significant difference in the proportion who had had a rigid sigmoidoscopy in the preceding 10 years. Although this study suggests that patients with fatal rectal cancer were less likely than matched control patients to have had rigid sigmoidoscopy in the preceding 10 years, adenomas were detected with sigmoidoscopy and removed in only $12(1 \%)$ of the 868 control patients. Detection and successful treatment of neoplasia as a result of sigmoidoscopy are needed to infer that survival was due to screening with sigmoidoscopy. That only a small proportion of patients had polypectomy suggests that there may be intrinsic differences between the groups, resulting from the case-control design rather than from a treatment effect.

A similar case control study was reported by Newcomb and colleagues (39). All subjects in the study were members of a health plan during the study period 1979 to 1988 . Individuals in the case group had died of cancer of the colon or rectum. This study included only 74 case subjects (of whom 66 had medical records available) and 206 control subjects (of whom 196 were included). There was no significant difference in the proportion of subjects who had had FOBT (21\% of case subjects compared with $16 \%$ of control subjects). However, $30 \%$ of control subjects compared with $10.6 \%$ of case subjects had had a sigmoidoscopy (odds ratio $0.21 ; 95 \%$ CI 0.08 to 0.52 ). The reduction was in cases with cancers limited to the rectum and distal colon only. The proportion of subjects who had a polypectomy with the sigmoidoscopy was not reported.

A third case control study was reported by Muller and Sonnenberg (40), who studied more than 30,000 individuals followed by the Veteran Affairs in the United States. There were 8722 individuals who had died of a colon cancer and 7629 who had died of a rectal cancer, plus matched controls. The two groups were assessed for the proportion who had undergone an endoscopic procedure (flexible sigmoidoscopy, colonoscopy, polypectomy) between 1981 and the time of diagnosis of their cancer. The likelihood of a patient dying of a colon cancer having had an endoscopic procedure was 0.51 (95\% CI 0.44 to 0.58 ) compared with the control subjects, and the likelihood of a patient dying of a rectal cancer having had a sigmoidoscopy was 0.55 (95\% CI 0.47 to 0.64 ).

Two large descriptive studies with adequate follow-up (level III evidence) have provided evidence that screening with sigmoidoscopy can decrease mortality from colorectal cancer compared with the normal population (41-43). However, because both of these studies were uncontrolled, the effects of volunteer, lead time and length time bias cannot be measured.

Verne and colleagues (44) conducted a small RCT comparing FOBT with flexible sigmoidoscopy or both to determine the feasibility of such a study. The study comprised 3744 patients between 50 and 75 years of age who were randomly assigned by household to one of the three groups. Compliance was significantly higher in the group of patients randomly assigned to flexible sigmoidoscopy than in the other two groups (46.6\% compared with $31.6 \%$ and $30.1 \%$, respectively). Polyp and cancer detection data but no mortality data were available. Although polyps were detected in $17 \%$ of individuals, they were adenomas in only $6.8 \%$ and high risk adenomas in $2.4 \%$. Cancers were found in $0.4 \%$. The addition of FOBT did not improve the detection rate. Eighty-one subjects who had a negative FOBT had polyps detected at flexible sigmoidoscopy, including 30 with adenomas and one with an early cancer. Based on the histology of the polyps removed at flexible sigmoidoscopy, $7 \%$ of subjects required follow-up colonoscopy. Because not all patients underwent colonoscopy, the false negative rate cannot be calculated.

In another RCT, subjects were randomly assigned to FOBT, or combined FOBT and flexible sigmoidoscopy (45). In total, 6371 individuals between 50 and 74 years of age were randomly assigned to the two groups. In both groups, the compliance with FOBT was $48 \%$ to $50 \%$, whereas only $20 \%$ of individuals in the combined group agreed to undergo flexible sigmoidoscopy. Despite this, the neoplasia detection rate was four times higher in the FOBT/flexible sigmoidoscopy group (8.9 patients per 1000 screened compared with 2.0 per 1000 screened). This difference was largely due to the addition of flexible sigmoidoscopy. Twenty-two patients (including two with cancers) were identified by flexible sigmoidoscopy compared with only six or seven individuals with FOBT.

In a third trial, reported by Rasmussen et al (46), 5495 individuals between 50 and 75 years of age were randomly assigned to FOBT and flexible sigmoidoscopy, and 5483 to FOBT alone. There was lower compliance in the FOBT/flexible sigmoidoscopy group (40\% versus 50\%). However, 12 colorectal cancers and 72 large adenomas were detected in this group compared with four colorectal cancers and 14 large adenomas in the group that underwent FOBT only. There are no data available on mortality.

Thus, there is evidence from three case-control studies that sigmoidoscopy may reduce the risk of death from colorectal cancer. Three RCTs suggest that flexible sigmoidoscopy may be superior to FOBT in detecting adenomas and possibly cancer (44-46). However, the latter trials are small and do not report mortality data. Therefore, the benefit of flexible sigmoidoscopy alone compared with FOBT or in combination with FOBT cannot be ascertained. However, there is fair evidence to suggest that sigmoidoscopy may reduce mortality from colorectal cancer. Flexible sigmoidoscopy may be preferable to rigid sigmoidoscopy because the physician can examine the more proximal colon better with the flexible sigmoidoscope than with the rigid one, and thus detect more adenomas and carcinomas (47). The flexible sigmoidoscope may be more acceptable to patients and safer (48). With flexible sigmoidoscopic examinations, bowel perforations occur at a rate of 1.4 per 10,000 asymptomatic patients (49); a more qualified examiner is required than with rigid sigmoidoscopy.

Further data are required regarding the frequency of examinations, compliance and feasibility of performing the 
screening flexible sigmoidoscopy as well as the colonoscopic follow-up examinations. As well, further data regarding the significance of small polyps identified at flexible sigmoidoscopy and the need for colonoscopic examination are required because there is controversy regarding the significance of polyps less than $0.5 \mathrm{~cm}$ in size (50-53). Finally, an RCT comparing once-only screening with flexible sigmoidoscopy at age 60 years with no screening is being performed in the United Kingdom (The Flexible Sigmoidoscopy screening trial [FLEXISCOPE]) $(54,55)$. A second trial is the United States National Cancer Institute Prostate, Lung, Colorectal \& Ovarian Cancer Screening Trial (PLCO) (56). The results of these trials will further elucidate the value of screening with flexible sigmoidoscopy.

Uniphase screening with colonoscopy: There is no direct evidence about the effectiveness of colonoscopy as a screening manoeuvre in asymptomatic, average risk individuals. However, as stated previously, $38 \%$ of individuals in the group who were screened annually in the University of Minnesota trial underwent colonoscopic examination, and there was a RR reduction in mortality from colorectal cancer of $33 \%(\mathrm{RR}=0.67 ; 95 \% \mathrm{CI} 0.50$ to 0.87$)$ compared with control subjects (17). Furthermore, after reanalyzing the data, Lang and Ransohoff (34) concluded that at least some of the reduction in mortality was due to chance selection of individuals for colonoscopy and, if so, perhaps less frequent screening with colonoscopy might be more appropriate than initial screening with Hemoccult testing.

The National Polyp study was an RCT designed to determine the optimal frequency of colonoscopy in individuals who had previously had a polypectomy (57). As a secondary analysis, the investigators compared the incidence of cancer in this cohort of patients with that of two historical control groups where polyps had not been removed (patients from St Mark's Hospital, London, United Kingdom, and the Mayo Clinic, Rochester, Minnesota) and one general population registry (the Surveillance, Epidemiology, and End Results [SEER] program data). In the 1418 individuals in the National Polyp Study, five early asymptomatic cancers were detected by colonoscopy within the mean follow-up time of 5.9 years. The predicted rates in the reference groups were 48.3, 43.4 and 20.7, for reductions in the incidence of colorectal cancer of $90 \%, 88 \%$ and $76 \%$, respectively. This study is obviously limited by the biases of a study where patients are followed prospectively and compared with historical controls. Nevertheless, it provides some evidence (level II-3) that colonoscopy may decrease the risk of cancer, although it provides no evidence that mortality is reduced.

Four uncontrolled trials (level III evidence) involving asymptomatic patients over 50 years of age with no family history of colorectal cancer have been reported (53,58-60). Because there were no control groups or follow-up, there is no direct evidence for or against the effectiveness of screening asymptomatic patients with colonoscopy. Several important points were, however, noted in these studies. The incidence of carcinomas (0.01) and the incidence of adeno- mas (0.22) were higher with colonoscopy than with the Hemoccult test. Compliance rates were variable, ranging from $6 \%$ to $49 \%(53,60)$.

Screening above average risk groups: Individuals belonging to FAP and HNPCC kindreds have close to a $50 \%$ chance of developing colorectal cancer because of the autosomal dominant mode of inheritance of these syndromes. Similarly, individuals with a family history of colorectal cancer but who do not fit the criteria for HNPCC or FAP may be at increased risk, although that risk is less well defined. Finally, ulcerative colitis and a past history of adenomatous polyps or colorectal cancer increase the chance of developing a colorectal cancer. As mentioned above, patients with ulcerative colitis, and a history of polyps or cancer were omitted from this review because both groups have identifiable diseases, although the latter may be asymptomatic.

Individuals at risk for FAP: FAP is characterized by the progressive development of multiple adenomatous polyps occurring throughout the colon (61). Generally, polyps first appear after puberty. If left untreated, $100 \%$ of individuals will develop a colon cancer, on average by age 40 years. While colorectal polyps and cancer are the common manifestation of this disease, other benign and malignant lesions, including gastric and duodenal polyps, desmoid tumours, osteomas and retinal lesions (congenital hypertrophic retinal pigment epithelium) occur with variable frequency. FAP is transmitted through an autosomal dominant gene so that approximately $50 \%$ of individuals at risk will be affected. Approximately $10 \%$ to $15 \%$ of affected individuals give no family history, and the disease is thought to arise because of a spontaneous mutation.

There are data from retrospective cohort studies of registry data that the survival of screened individuals is significantly better than that of probands (level II-3 evidence) (62). Because polyps are almost always present in the rectum before the development of a colorectal cancer, screening with flexible sigmoidoscopy in individuals at risk beginning at puberty and continuing at one- or two-year intervals has been the accepted routine.

With the identification of the APC gene on chromosome 5 , it is now possible to perform genetic testing in at risk individuals (63-65). In families where the genetic mutation has been identified, the sensitivity and specificity of genetic testing are $100 \%$ (66). Furthermore, this strategy has been shown to be cost effective compared with surveillance with flexible sigmoidoscopy (67). The advantage of genetic testing is that it is noninvasive and may be more acceptable to patients. The disadvantage of genetic testing is that the gene mutation may be identified in only $70 \%$ of affected families. Furthermore, genetic testing may not be widely available.

Individuals at risk for HNPCC: HNPCC is typified by the presence of multiple family members affected with cancer, including cancers of the colon and rectum, as well as the endometrium, stomach, small bowel, pancreas, ovary, and ureter and renal pelvis in some families (68). 
Approximately $2 \%$ to $5 \%$ of all colorectal cancers fit the criteria for HNPCC (69-72). Because HNPCC is inherited as an autosomal dominant trait with high penetrance, the risk of a family member of an HNPCC pedigree being affected nears $50 \%$. In those who are affected, the risk of colorectal cancer is estimated to be approximately $70 \%$ by age 65 years $(73)$.

In HNPCC, colorectal cancers tend to be right sided and occur at an early age, and there is an excess of synchronous and metachronous colon cancers. There is a greater incidence of polyps than in age-matched controls, although not the large numbers seen in FAP. Cancers tend to have poor prognostic histological features (poorly differentiated, mucinous) and be more advanced at presentation. Despite this, the prognosis is better than sporadic tumours of equivalent stage. Because the phenotype of HNPCC tumours is not as unique as with FAP, various criteria have been developed to define kindreds with HNPCC. Of these, the Amsterdam criteria are most widely accepted (74). Using the Amsterdam Criteria, an HNPCC kindred must have three individuals affected with colorectal cancer, with two being in successive generations and at least one being under the age of 45 years. FAP must be excluded. However, despite their value in standardizing reporting of HNPCC, these criteria have relatively low sensitivity and specificity in discriminating between families where there is clustering of sporadic cancers and HNPCC (75; and unpublished data).

HNPCC cancers differ from sporadic cancers in that approximately $85 \%$ of cancers exhibit microsatellite instability compared with approximately $10 \%$ to $20 \%$ in sporadic cancers (71). Six germline mutations (hMSH2, hMLH1, hPMS1, hPMS2, hMSH3 and hMSH6/GTBP) have been identified, all involving genes involved in DNA mismatch repair. These mutations are not unique to HNPCC (68). Furthermore, germline mutations may be identified in only $50 \%$ of high risk families suspected of having HNPCC (75; and unpublished data). Thus, at the present time, genetic testing is not feasible to identify HNPCC families but is of value in testing members of HNPCC families where a mutation has been identified.

Because approximately $45 \%$ of cancers are right sided in HNPCC families, colonoscopy is the preferred method of screening. Based on expert opinion, colonoscopy, beginning at age 20 to 25 years and repeated at one- to three-year intervals, has been recommended (76). A short interval between examinations is based on evidence that the adenoma-cancer sequence may be shortened in HNPCC (73). There are no RCTs showing that colonoscopy increases survival or decreases the incidence of colon cancer in individuals at risk in HNPCC families. The only evidence comes from retrospective observational data. Vasen and colleagues (77) reported data from the Netherlands Registry, where 388 asymptomatic first-degree relatives underwent colonoscopy, or double-contrast barium enema and flexible sigmoidoscopy at two- to three-year intervals and compared the results with those of 238 individuals who did not undergo surveillance. Cancers in the surveillance group were detected earlier (73\% Dukes' A or B compared with $47 \%$ in the nonsurveillance group) and had better survival (87\% versus $63 \%$ respectively). Jarvinen and colleagues (78) reported 133 individuals at risk who had colonoscopy at three-year intervals and 119 at risk subjects who did not have any screening. Colorectal cancer occurred in eight (6\%) screened individuals compared with 19 (16\%) unscreened individuals $(\mathrm{P}=0.014)$. As well, the tumour stage of the cancers was more favourable in the screened group. There were no cancer deaths in the screened group compared with nine colorectal cancer deaths in the unscreened group $(\mathrm{P}<0.001)$. In addition, the overall mortality rate was significantly lower in the screened group (26 versus 10 deaths, $\mathrm{P}=0.003)$. With respect to the frequency of screening, four of the eight cancers detected by screening by Jarvinen et al (78) occurred in individuals who had been screened between 26 and 37 months earlier. In the Dutch study, four of 11 cancers occurred between two and four years after a negative screen. Lanspa and colleagues (79) reported that six cancers arose in 225 individuals within four years of colonoscopic surveillance and another 17 developed a metachronous cancer within five years of resection of their first colon cancer.

Vasen and colleagues (80) constructed a model comparing a strategy of surveillance with colonoscopy every two to three years and no surveillance in individuals who were known to be gene carriers. Their results showed that surveillance would lead to an increase in life expectancy of seven years and the costs of surveillance under a wide range of assumptions were less than the costs of no surveillance.

Individuals with a family history of polyps or colon cancer: Several studies have indicated that individuals with a family history of colorectal cancer are at a higher risk for developing colorectal cancer. Family history data on colorectal cancer were collected in the Health Professionals Follow-up study and The Nurses Health Study (81). Overall, a history of colorectal cancer in a first-degree relative was reported by $9.4 \%$ of the 32,085 men in the Health Professionals Follow-up Study and by $10 \%$ of women in the Nurses Health Study. During the study period, colorectal cancer was diagnosed in 148 of the men and 315 of the women. Seventeen per cent of these had previously reported a family history of colorectal cancer. For those with a family history, the age-adjusted RR of colorectal cancer was 1.64 (95\% CI 1.04 to 2.58) for men and 1.77 (95\% CI 1.32 to 2.37 ) for women. The likelihood of a family history of colorectal cancer was higher in younger participants with colorectal cancer (for individuals 30 to 44 years of age, $\mathrm{RR}=5.37$; $95 \% \mathrm{CI} 1.98$ to 17.4 ). There was also an increased risk of colorectal cancer as the number of affected relatives increased. Thus, with two or more affected firstdegree relatives, the age-adjusted RR of colorectal cancer was 2.75 (95\% CI 1.34 to 5.63 ).

Winawer and colleagues (82) obtained a family history of colorectal cancer and analyzed the data from 1199 participants in the National Polyp Study. The RR of colorectal cancer was 1.78 for parents and siblings of the patients with 
adenomas compared with spouse controls (95\% CI 1.18 to 2.67). The risk increased if the proband was younger than 60 years (for siblings $\mathrm{RR}=2.59 ; 95 \% \mathrm{CI} 1.46$ to 4.58 ) and continued to increase as the age of the proband decreased. The risk in siblings also increased if there was a parent with colorectal cancer as well as the proband $(\mathrm{RR}=3.25 ; 95 \% \mathrm{CI}$ 1.92 to 5.52$)$. Similar results were reported by Ahsan et al (83), who performed a similar study in patients found to have adenomas during an initial colonoscopy compared with a control group with a negative colonoscopy. They also found that the risk of colorectal cancer increased in first-degree relatives as the age of the proband decreased. St John and colleagues (84) performed a case-control study in which the cases were patients with colorectal cancers. Again, the risk increased as the number of affected first-degree relatives increased $(\mathrm{RR}=1.8 ; 95 \% \mathrm{CI} 1.2$ to 2.7 for those with one affected relative and $\mathrm{RR}=5.7$; $95 \%$ CI 1.7 to 19.3 for those with two affected relatives). As well, the risk of colorectal cancer increased in parents and siblings as the age of the index case decreased $(\mathrm{OR}=3.7$; $95 \%$ CI 1.5 to 9.1 for case patients diagnosed before age 45 years and $\mathrm{OR}=1.895 \% \mathrm{CI}$ 1.2 to 2.9 for case patients diagnosed after age 45 years).

Despite this increased risk, there is little evidence on how to screen individuals with a family history of colorectal cancer and whether a more intensive screening program is needed or effective. In particular, no RCTs or other studies have compared FOBT with colonoscopy for screening. Furthermore, the only published studies reported detection rates but were too small to report survival data.

Rozen and colleagues (85) initially screened 471 asymptomatic first-degree relatives of patients with colorectal cancer with Hemoccult tests and sigmoidoscopy. They compared the results with those from a group of 457 asymptomatic volunteers with no family history of colorectal cancer. The prevalence of neoplasia (both adenomas and carcinomas) was three times higher in the group with a family history than in the control group. However, only two invasive carcinomas were detected in the study group (for a detection rate of 0.004 ), compared with one in the control group (for a detection rate of 0.002). There were three times as many colonoscopic examinations in the study group as in the control group, despite there being no significant difference in the rate of positive results of Hemoccult tests or of positive results of sigmoidoscopic examinations. Hence, a diagnostic suspicion bias may explain some of the difference in the rate of detection of neoplasia (86).

Pariente and colleagues (87) offered colonoscopy to first-degree relatives of 195 recently diagnosed individuals with colorectal cancer. Two control subjects who had colonoscopy for a reason unrelated to colorectal cancer were selected from the same centre. Adenomas were found in 43 $(23.2 \%)$ relatives and $64(17.5 \%)$ control subjects. No cancers were detected in either group. ORs were $1.5(95 \%$ CI 1.0 to 2.4) for detection of an adenoma and 2.6 (95\% CI 1.3 to 5.1 ) for a high risk adenoma (defined as a polyp greater than $1 \mathrm{~cm}$ or with a villous component) in the relatives group compared with the controls. Furthermore, the risk of a high risk adenoma increased if the index case was under 65 years of age, male or had a left-sided or advanced cancer.

Guillem and colleagues (88) compared the colonoscopic results of 181 first-degree relatives with those of a control group without a family history of colorectal cancer. Adenomatous polyps were detected in $14.4 \%$ of the individuals with a family history compared with $8.4 \%$ of individuals in the control group. Again, no cancers were detected.

In a study from Scandinavia, the results of colonoscopy in 50 relatives were compared with those of 308 asymptomatic controls (89). The risk of adenoma was twice as high in the first-degree relatives, but this difference was observed only in females.

Finally, despite the increased risk of developing adenomas or cancers, compliance rates for screening colonoscopy among first-degree relatives have been low in most studies. Only $39 \%$ to $42 \%$ of first-degree relatives offered colonoscopy in the studies by Pariente et al (87) and Guillem et al (88) accepted the invitation. Furthermore, although $42 \%$ of the relatives offered colonoscopy accepted the invitation in the study by Guillem et al (88), only $47 \%$ of individuals with cancer agreed to have their relatives contacted. Thus, only approximately $20 \%$ of individuals at risk had a screening colonoscopy. The compliance rate reported by the Norwegian group was much higher (82\%) (89).

\section{DISCUSSION}

The evidence for the various interventions is summarized in Table 3.

Average risk individuals - Screening with the Hemoccult test: There is good evidence from RCTs (level I) that screening with the Hemoccult test reduces mortality in asymptomatic patients older than 50 years with no other risk factors. The RR of colorectal cancer death with Hemoccult screening is $0.84(95 \% \mathrm{CI} 0.77$ to 0.93$)$ overall and 0.77 (95\% CI 0.57 to 0.89 ) in those who are compliant. However, there remain concerns about the high rate of false-positive results, feasibility and small clinical benefit of such screening (over 1000 individuals must be screened for 10 years to avert one death from colorectal cancer). There is some suggestion that patients being screened with Hemoccult should avoid red meat, cantaloupe and melons, raw turnip, radishes, broccoli and cauliflower, vitamin C supplements, and acetylsalicylic acid and other nonsteroidal antiinflammatory drugs for three days before fecal samples are collected. However, a recent meta-analysis of four RCTs found no improvement in positivity rates or change in compliance rates with moderate dietary restrictions (90).

Screening with sigmoidoscopy: There is evidence from case control studies (level II-2) that flexible sigmoidoscopy reduces the mortality from colorectal cancer in those over age 50 years, although the evidence regarding whether only one or both of FOBT and sigmoidoscopy should be performed is unclear.

Screening with colonoscopy: The evidence is unclear regarding the use of colonoscopy as an initial screen. Although colonoscopy is the best method for diagnosing 
TABLE 3

Summary of evidence for screening strategies to detect colorectal cancer (CRC) in asymptomatic patients

\begin{tabular}{|c|c|c|}
\hline Manoeuvre & Effectiveness & Level of evidence (reference) \\
\hline \multicolumn{3}{|l|}{ Average risk } \\
\hline $\begin{array}{l}\text { Multiphase screening with the } \\
\text { Hemoccult test for average risk } \\
\text { adults older than age } 50 \text { years }\end{array}$ & $\begin{array}{l}\text { RR of CRC* death with screening with } \\
\text { Hemoccult testing is } 0.84(95 \% \mathrm{Cl} 0.77 \text { to } 0.93) \text { overall and } \\
0.77(95 \% \mathrm{Cl} 0.57 \text { to } 0.89) \text { in those who are compliant } \\
\mathrm{NNT}=1173 \text { over } 10 \text { years }\end{array}$ & $\begin{array}{l}\text { Randomized controlled trials and } \\
\text { meta-analysis (I) }(16-28)\end{array}$ \\
\hline $\begin{array}{l}\text { Sigmoidoscopy for average risk adults } \\
\text { older than age } 50 \text { years }\end{array}$ & $\begin{array}{c}\text { Patients with rectal cancers were less likely to } \\
\text { have had a sigmoidoscopy in the } \\
\text { previous } 10 \text { years }\end{array}$ & $\begin{array}{l}\text { Case-control studies (37-40) (II-2) } \\
\text { and case series (41-43) (III) }\end{array}$ \\
\hline $\begin{array}{l}\text { Hemoccult/sigmoidoscopy in } \\
\text { combination for average risk adults } \\
\text { older than age } 50 \text { years }\end{array}$ & $\begin{array}{l}\text { Some evidence that the addition of flexible } \\
\text { sigmoidoscopy increases the detection rate of } \\
\text { adenomas and colorectal cancer } \\
\text { No mortality data }\end{array}$ & RCT (I) (44-46) \\
\hline Colonoscopy & $\begin{array}{l}\text { Indirect evidence from RCT showing decreased } \\
\text { colorectal cancer mortality }\end{array}$ & II-3 $(19,57)$ \\
\hline \multicolumn{3}{|l|}{ Above average risk } \\
\hline $\begin{array}{l}\text { Flexible sigmoidoscopy for those } \\
\text { with FAP }\end{array}$ & $\begin{array}{l}\text { The risk of death from colorectal cancer } \\
\text { may be decreased }\end{array}$ & II-3 (62) \\
\hline Genetic testing for those with FAP & $\begin{array}{l}\text { The risk of death from colorectal cancer } \\
\text { may be decreased }\end{array}$ & II-3 (63-67) \\
\hline Colonoscopy for those with HNPCC & The risk of neoplasia may be decreased & II-3 (78-80) \\
\hline $\begin{array}{l}\text { Colonoscopy for those with a family } \\
\text { history of polyps/CRC (first-degree } \\
\text { relatives) }\end{array}$ & $\begin{array}{c}\text { There is evidence of increased prevalence of neoplasms } \\
\text { in these individuals but insufficient information } \\
\text { to recommend more intense screening }\end{array}$ & III (82-90) \\
\hline
\end{tabular}

adenomas and carcinomas, it may not be feasible to screen asymptomatic patients because of patient compliance, the expertise and equipment required, and the potential costs. On the other hand, if colonoscopy were an effective screening strategy when performed at less frequent intervals, these issues might be of less concern.

Above average risk individuals - Individuals at risk for FAP: There is fair (level II-3) evidence to support genetic testing of individuals at risk for FAP if the genetic mutation has been identified in the family and if genetic testing is available. If the individual carries the mutation, the evidence indicates that screening with flexible sigmoidoscopy should begin at puberty. Individuals from families where the gene mutation has been identified, but who are negative themselves, require screening similar to the average risk population. For individuals at risk in whom the mutation has not been identified in the family, or where genetic testing is not available, the evidence indicates that screening with annual or biannual flexible sigmoidoscopy should be undertaken beginning at puberty. In all instances, genetic counselling is indicated before genetic testing.

Individuals at risk for HNPCC: Patients in kindreds with the cancer family syndrome HNPCC have a high risk of colorectal cancer and a high incidence of right-sided colon cancer. There is a lower level of evidence (level III) available regarding screening in individuals from HNPCC kindreds. It is important to note, however, that it is unlikely that more rigorous studies could be performed in this cohort of patients given the high risk of cancer and relative infrequency of HNPCC, and practice should be guided accordingly. There is no evidence regarding the age when screening should begin and the frequency at which colonoscopy should be performed.

Individuals with a family history of polyps or colon cancer: The evidence indicates that patients who have only one or two first-degree relatives with colorectal cancer should be screened in the same way as average risk individuals. There is insufficient evidence to recommend colonoscopy or other screening tests in individuals who have a family history of colorectal polyps or cancer but do not fit the criteria for HNPCC. While there is evidence of an increased prevalence of neoplasms in these individuals, there is insufficient information regarding whether these individuals would benefit from more intense screening than that given to individuals at average risk. Further delineation of the risk for individuals with multiple affected family members and family members with early age of diagnosis of colorectal cancer is necessary. 
Because most screening options are multiphasic, an adequate infrastructure is needed to support implementation, and assure quality control, and optimal and timely followup of screened individuals.

It is useful to compare the results of this systematic review with existing guidelines for CRC screening. Despite there being level 1 evidence on the benefit of screening average risk individuals with Hemoccult testing, existing recommendations are variable due to concern over test sensitivity. Of the three RCTs that reported mortality data, only that by Hardcastle et al (25) recommended institution of a national screening program with FOBT. Kronborg and colleagues (23) considered it to be a feasible option until better screening methods become available. Mandel and colleagues (17) made no recommendations but did cite concerns about the cost of a screening program. After performing the meta-analysis, Towler and colleagues (28) concluded that screening with Hemoccult is likely to result in a net benefit, but stated that there are still some important issues to be answered and that these questions require further evaluation.

In Canada, the Ontario Expert Panel on Colorectal Screening recommended (in 1999) that a program of colorectal cancer screening using a multiphase program including initial screening with FOBT should be adopted for individuals with average risk between 50 and 75 years of age (91). To date, no recommendations have been made for individuals at increased risk.

The United States Preventive Services Task Force also recommended (in 1996) screening for individuals over age 50 years with either annual FOBT or sigmoidoscopy (interval unspecified) or both (9). A number of organizations in the United States, including the American Cancer Society, the American College of Gastroenterology, the American Gastroenterological Association, the American Society of Colon and Rectal Surgeons, the American Society for Gastrointestinal Endoscopy, the Crohn's and Colitis Foundation of America, the Oncology Nursing Society and the Society of American Gastrointestinal Endoscopic Surgeons, recommended (in 1997) screening with FOBT annually; flexible sigmoidoscopy every five years; combined FOBT and flexible sigmoidoscopy at the same intervals as for the individual procedures; double-contrast barium enema every five to 10 years; or colonoscopy every 10 years for individuals aged 50 years or older, with no other risk factors (92). This group also made recommendations for those with additional risk factors. Thus, they recommended genetic counselling and possible genetic testing for those at risk for FAP. For those who are positive, flexible sigmoidoscopy beginning at puberty is recommended. For HNPCC kindred, colonoscopy annually beginning between the ages of 20 and 30 years is recommended. Finally, these groups made similar recommendations for individuals with a family history of polyps/cancer as for those with average risk but beginning at age 40 years rather than at age 50 years.

The Australian Health Technology Advisory Committee recommended (in 1997) the establishment of pilot and feasibility studies to assess screening programs in the Australian context (13). They recommended screening with FOBT in the average risk population over the age of 50 years, but given the uncertainties, the program should commence with preliminary testing.

The Italian National Committee for Colorectal Cancer Prevention (in 1996) found no evidence to support mass screening, and recommended a centrally coordinated intervention program to evaluate the effectiveness of screening (93).

In New Zealand, The National Health Committee Working Party on Screening for Colorectal Cancer advised against population-based screening for colorectal cancer with FOBT, or any other modality given the modest potential benefit by the former and lack of evidence for other modalities (94).

Further research is required to develop a screening test that is more sensitive than the Hemoccult, and less costly and invasive than colonoscopy, yet capable of detecting neoplasia in the entire colon and rectum. Development of such a test is a high research priority, given that survival rates can be improved by screening, even with an insensitive technique, that colorectal cancer represents a significant burden of illness in Western societies and that early detection is known to improve survival rates. Virtual colonoscopy is a promising screening test, although further evaluation is required (95).

More data regarding both the effectiveness and the acceptance of colonoscopic screening are needed. Data on the timing (ie, age of onset) and frequency of colonoscopy are also needed because it is possible that, if screening with colonoscopy were effective if performed infrequently or even once only (for asymptomatic individuals), it might be feasible, acceptable and cost effective (96).

Efforts to identify high risk groups (through genetic counselling, for example) and to develop targeted strategies for these groups may be appropriate. More information on the genetic basis of HNPCC is needed, as is a better means of identifying high risk families requiring screening. Research efforts should also aim to determine the true risk of colorectal cancer in subgroups with family history of neoplasia, especially those with multiple family members where cancer occurred at a young age.

ACKNOWLEDGEMENTS: The Canadian Task Force on Preventive Health Care is funded through a partnership between the Provincial and Territorial Ministries of Health and Health Canada. The author and Task Force thank Drs Alexandra Barratt, Department of Public Health and Community Medicine, University of Sydney, Sydney, Australia; Paul Frame, Tri-County Family Medicine, Cohocton, New York and United States Preventive Services Task Force; Michael Pignone, Division of General Internal Medicine, University of North Carolina at Chapel Hill, Chapel Hill, North Carolina; and Jerome Simon, Division of Gastroenterology, Queen's University, Kingston, Ontario, for reviewing a draft form of this manuscript. The views expressed in this report are those of the author and the Canadian Task Force, and do not necessarily reflect the positions of the reviewers. 


\section{APPENDIX 1 \\ Members of the Canadian Task Force on Preventive Health Care}

Chairman: Dr John W Feightner, Department of Family Medicine, The University of Western Ontario, London, Ontario

Past chairman: Dr Richard Goldbloom, Department of Pediatrics, Dalhousie University, Halifax, Nova Scotia.

Members: Drs R Wayne Elford, Department of Family Medicine, University of Calgary, Calgary, Alberta; Denice Feig, Department of Endocrinology, University of Toronto, Toronto, Ontario; Michel Labrecque, Unité de médecine familiale, Université Laval, Rimouski, Québec; Harriet MacMillan, Departments of Psychiatry \& Behavioural Neurosciences \& Pediatrics, Canadian Centre for Studies of Children at Risk, McMaster University, Hamilton, Ontario; Robin McLeod, Departments of Surgery and Health Administration, Mount Sinai Hospital and University of Toronto, Toronto, Ontario; Jean-Marie Moutquin, Département d'obstétrique-gynécologie, Université de Sherbrooke, Sherbrooke, Québec; Valerie Palda, Department of General Internal Medicine, University of Toronto, Toronto, Ontario; Christopher Patterson, Division of Geriatric Medicine, Department of Medicine, McMaster University, Hamilton, Ontario; Elaine EL Wang, Departments of Pediatrics and of Public Health Sciences, Faculty of Medicine, University of Toronto, Toronto, Ontario.

Resource people: Nadine Wathen and Ruth Walton, Canadian Task Force on Preventive Health Care, Department of Family Medicine, The University of Western Ontario, London, Ontario.

\section{REFERENCES}

1. Canadian Cancer Statistics 2000. Toronto: National Cancer Institute of Canada, 2000.

2. Wilson SM, Beahrs OH. The curative treatment of carcinoma of the sigmoid, rectosigmoid, and rectum. Ann Surg 1976;183:556-65.

3. Toribara NW, Sleisenger MH. Screening for colorectal cancer. N Engl J Med 1995;332:861-7.

4. Solomon MJ, McLeod RS. Periodic health examination, 1994 update: 2. Screening strategies for colorectal cancer. Canadian Task Force on the Periodic Health Examination. CMAJ 1994;150:1961-70.

5. Simon JB. Fecal occult blood testing: clinical value and limitations. Gastroenterologist 1998;6:66-78.

6. Ahlquist DA, McGill DB, Schwartz S, Taylor WF, Owen RA. Fecal blood levels in health and disease. A study using HemoQuant. N Engl J Med 1985;312:1422-8.

7. Allison JE, Tekawa IS, Ransom LJ, Adrain AL. A comparison of fecal occult-blood tests for colorectal-cancer screening. N Engl J Med 1996;334:155-9.

8. Robinson MH, Marks CG, Farrands PA, Thomas WM, Hardcastle JD. Population screening for colorectal cancer: comparison between guaiac and immunological faecal occult blood tests. Br J Surg 1994;81:448-51.

9. US Preventive Services Task Force. Screening for colorectal cancer. Guide to Clinical Preventive Services. Alexandria: International Medical Publishing Inc, 1996:89-103.

10. Cummings BJ. A critical review of adjuvant preoperative radiation therapy for adenocarcinoma of the rectum. Br J Surg 1986;73:332-8.

11. Vogelstein B, Fearon ER, Hamilton SR, et al. Genetic alterations during colorectal-tumor development. N Engl J Med 1988;319:525-32.

12. Stephenson BM, Finan PJ, Gascoyne J, Garbett F, Murday VA, Bishop DT. Frequency of familial colorectal cancer. Br J Surg 1991;78:1162-6.

13. Colorectal Cancer Screening. A Report of the Australian Health Technology Advisory Committee. Canberra: Australian Health Technology Advisory Committe, 1997.

14. Lennard-Jones JE, Melville DM, Morson BC, Ritchie JK, Williams CB. Precancer and cancer in extensive ulcerative colitis: findings among 401 patients over 22 years. Gut 1990;31:800-6.

\section{APPENDIX 2 \\ Methodology of the Canadian Task Force on Preventive Health Care}

Critical appraisal: A manuscript providing critical appraisal of the evidence for this topic was prepared by the lead author. This included identification and critical appraisal of key studies, and ratings of the quality of this evidence using the Task Force's established methodological hierarchy (sidebar), which resulted in a summary of proposed conclusions and recommendations for consideration by the Task Force.

Consensus development: Evidence for this topic was presented by the lead author and deliberated upon during Task Force meetings in January and June 1999, and January 2000. Expert panelists addressed critical issues, clarified ambiguous concepts and analyzed the synthesis of the evidence. At the end of this process, the specific clinical recommendations proposed by the lead author were discussed, as were issues related to clarification of the recommendations for clinical application and any gaps in evidence. The results of this process are reflected in the description of the decision criteria presented with the specific recommendations. The group and lead author arrived at final decisions on recommendations unanimously. Subsequent to the meetings, the lead author revised the manuscript accordingly. After final revision, the manuscript was sent by the Task Force to four experts in the field (identified by Task Force members at the meeting). Feedback from these experts was incorporated into a subsequent draft of the manuscript, which was then submitted to The Canadian Journal of Gastroenterology. Procedures to achieve adequate documentation, consistency, comprehensiveness, objectivity and adherence to the Task Force methodology were maintained at all stages during review development, the consensus process and beyond to ensure uniformity and impartiality throughout.

\section{Levels of evidence}

I Evidence from at least one well designed randomized controlled trial

II-1 Evidence from well designed controlled trials without randomization

II-2 Evidence from well designed cohort or case-control analytical studies, preferably from more than one centre or research group

II-3 Evidence from comparisons between times or places with or without the intervention; dramatic results from uncontrolled studies could be included here

III Opinions of respected authorities, based on clinical experience; descriptive studies or reports of expert committees

15. Woolf SH, Battista RN, Anderson GM, Logan AG, Wang E. Assessing the clinical effectiveness of preventive maneuvers: analytic principles and systematic methods in reviewing evidence and developing clinical practice recommendations. A report by the Canadian Task Force on the Periodic Health Examination. J Clin Epidemiol 1990;43:891-905.

16. Gilbertsen VA, Church TR, Grewe FJ, et al. The design of a study to assess occult-blood screening for colon cancer. J Chronic Dis 1980;33:107-14.

17. Mandel JS, Bond JH, Church TR, et al. Reducing mortality from colorectal cancer by screening for fecal occult blood. Minnesota Colon Cancer Control Study. N Engl J Med 1993;328:1365-71.

18. Mandel JS, Bond JH, Snover DC, et al. The University of Minnesota's Colon Cancer Control Study: Design and progress to date. In: Chamberlain J, Miller AB, eds. Screening for 
Gastrointestinal Cancer. Toronto: Huber, 1998:434-7.

19. Mandel JS, Bond JH, Bradley M, et al. Sensitivity, specificity, and positive predictivity of the Hemoccult test in screening for colorectal cancers. The University of Minnesota's Colon Cancer Control Study. Gastroenterology 1989;97:597-600.

20. Mandel JS, Church TR, Ederer F, Bond JH. Colorectal cancer mortality: effectiveness of biennial screening for fecal occult blood. J Natl Cancer Inst 1999;91:434-7.

21. Kronborg O, Fenger C, Olsen J, Bech K, Sondergaard O. Repeated screening for colorectal cancer with fecal occult blood test. A prospective randomized study at Funen, Denmark. Scand J Gastroenterol 1989;24:599-606.

22. Jensen BM, Kronborg O, Fenger C. Interval cancers in screening with fecal occult blood test for colorectal cancer. Scand J Gastroenterol 1992;27:779-82.

23. Kronborg O, Fenger C, Olsen J, Jorgensen OD, Sondergaard O. Randomised study of screening for colorectal cancer with faecaloccult-blood test. Lancet 1996;348:1467-71.

24. Hardcastle JD, Chamberlain JO, Robinson MH, et al. Randomised controlled trial of faecal-occult-blood screening for colorectal cancer. Lancet 1996;348:1472-7.

25. Hardcastle JD, Thomas WM, Chamberlain J, et al. Randomised, controlled trial of faecal occult blood screening for colorectal cancer. Results for first 107,349 subjects. Lancet 1989;i:1160-4.

26. Kewenter J, Brevinge H, Engaras B, Haglind E, Ahren C. Results of screening, rescreening, and follow-up in a prospective randomized study for detection of colorectal cancer by fecal occult blood testing. Results for 68,308 subjects. Scand J Gastroenterol 1994:29:468-73.

27. Kewenter J, Bjork S, Haglind E, Smith L, Svanvik J, Ahren C. Screening and rescreening for colorectal cancer. A controlled trial of fecal occult blood testing in 27,700 subjects. Cancer 1988;62:645-51.

28. Towler B, Irwig L, Glasziou P, Kewenter J, Weller D, Silagy C. A systematic review of the effects of screening for colorectal cancer using the faecal occult blood test, hemoccult. BMJ 1998;317:559-65.

29. Winawer SJ, Andrews M, Flehinger B, Sherlock P, Schottenfeld D, Miller DG. Progress report on controlled trial of fecal occult blood testing for the detection of colorectal neoplasia. Cancer 1980:45:2959-64.

30. Winawer SJ, Fleisher M, Baldwin M, Sherlock P. Current status of fecal occult blood testing in screening for colorectal cancer. CA Cancer J Clin 1982;32:100-12.

31. Winawer SJ, Schottenfeld D, Flehinger BJ. Colorectal cancer screening. J Natl Cancer Inst 1991;83:243-53.

32. Faivre J, Arveux P, Milan C, Durand G, Lamour J, Bedenne L. Participation in mass screening for colorectal cancer: results of screening and rescreening from the Burgundy study. Eur J Cancer Prev 1991;1:49-55.

33. Mandel JS, Church TR, Bond JH, et al. The effect of fecal occult blood screening on the incidence of colorectal cancer. N Engl J Med 2000;343:1603-7.

34. Lang CA, Ransohoff DF. Fecal occult blood screening for colorectal cancer. Is mortality reduced by chance selection for screening colonoscopy? JAMA 1994;271:1011-3.

35. Vernon SW. Participation in colorectal cancer screening: a review. J Natl Cancer Inst 1997;89:1406-22.

36. Blalock SJ, DeVellis BM, Sandler RS. Participation in fecal occult blood screening: a critical review. Prev Med 1987;16:9-18.

37. Friedman GD, Collen MF, Fireman BH. Multiphasic Health Checkup Evaluation: a 16-year follow-up. J Chronic Dis 1986;39:453-63.

38. Selby JV, Friedman GD, Quesenberry CP Jr, Weiss NS. A casecontrol study of screening sigmoidoscopy and mortality from colorectal cancer. N Engl J Med 1992;326:653-7.

39. Newcomb PA, Norfleet RG, Storer BE, Surawicz TS, Marcus PM. Screening sigmoidoscopy and colorectal cancer mortality. J Natl Cancer Inst 1992;84:1572-5.

40. Muller AD, Sonnenberg A. Protection by endoscopy against death from colorectal cancer. A case-control study among veterans. Arch Intern Med 1995;155:1741-8.

41. Gilbertsen VA. Proctosigmoidoscopy and polypectomy in reducing the incidence of rectal cancer. Cancer 1974;34(Suppl):9.

42. Gilbertsen VA, Nelms JM. The prevention of invasive cancer of the rectum. Cancer 1978;41:1137-9.

43. Hertz R, Deddish M, Day E. Value of periodic examinations in detecting cancer of the colon and rectum. Postgrad Med 1960;27:290-4

44. Verne JE, Aubrey R, Love SB, Talbot IC, Northover JM. Population based randomized study of uptake and yield of screening by flexible sigmoidoscopy compared with screening by faecal occult blood testing. BMJ 1998;317:182-5.

45. Berry DP, Clarke P, Hardcastle JD, Vellacott KD. Randomized trial of the addition of flexible sigmoidoscopy to faecal occult blood testing for colorectal neoplasia population screening. Br J Surg 1997;84:1274-6.

46. Rasmussen M, Kronberg O, Fenger C, Jorgensen OD. Possible advantages and drawbacks of adding flexible sigmoidoscopy to Hemoccult - II in screening for colorectal cancer. A randomized study. Scand J Gastroenterol 1999;34:73-8.

47. Grobe JL, Kozarek RA, Sanowski RA. Flexible versus rigid sigmoidoscopy: a comparison using an inexpensive $35-\mathrm{cm}$ flexible proctosigmoidoscope. Am J Gastroenterol 1983;78:569-71.

48. Winawer SJ, Miller C, Lightdale C, et al. Patient response to sigmoidoscopy. A randomized, controlled trial of rigid and flexible sigmoidoscopy. Cancer 1987;60:1905-8.

49. Winnan G, Berci G, Panish J, Talbot TM, Overholt BF, McCallum RW. Superiority of the flexible to the rigid sigmoidoscope in routine proctosigmoidoscopy. N Engl J Med 1980;302:1011-2.

50. Read TE, Read JD, Butterly LF. Importance of adenomas $5 \mathrm{~mm}$ or less in diameter that are detected by sigmoidoscopy. $\mathrm{N}$ Engl J Med 1997;336:8-12.

51. Atkin WS, Morson BC, Cuzick J. Long-term risk of colorectal cancer after excision of rectosigmoid adenomas. N Engl J Med 1992;326:658-62.

52. Imperiale TF, Wagner DR, Lin CY, Larkin GN, Rogge JD, Ransahoff DF. Risk of advanced proximal neoplasms in asymptomatic adults according to the distal colorectal findings. N Engl J Med 2000;343:169-74.

53. Lieberman DA, Weiss DG, Bond JH, Ahnen DJ, Garewal H, Chejfec G. Use of colonoscopy to screen asymptomatic adults for colorectal cancer. Veterans Affairs Cooperative Study Group 380 N Engl J Med 2000;343:162-8.

54. Atkin WS. Flexible sigmoidoscopy as a mass screening tool. Eur J Gastroenterol Hepatol 1998;10:219-23.

55. Atkin WS, Hart A, Edwards R, et al. Uptake, yield of neoplasia, and adverse effects of flexible sigmoidoscopy screening. Gut 1998;42:560-5.

56. Kramer BS, Gohagan J, Prorok PC, Smart C. A National Cancer Institute sponsored screening trial for prostatic, lung, colorectal, and ovarian cancers. Cancer 1993;71(2 Suppl):589-93.

57. Winawer SJ, Zauber AG, Ho MN, et al. Prevention of colorectal cancer by colonoscopic polypectomy. The National Polyp Study Workgroup. N Engl J Med 1993;329:1977-81.

58. Ballantyne GH, Savoca PE, Flemming FX, et al. Screening colonoscopy in asymptomatic patients. Dis Colon Rectum 1990;3(Suppl):14.

59. Johnson DA, Gurney MS, Volpe RJ, et al. A prospective study of the prevalence of colonic neoplasms in asymptomatic patients with an age-related risk. Am J Gastroenterol 1990;85:969-74.

60. Rex DK, Sledge GW, Harper PA, et al. Colonic adenomas in asymptomatic women with a history of breast cancer. Am J Gastroenterol 1993;88:2009-14.

61. Vasen HF, Griffioen G, Tops CM, et al. Familial adenomatous polyposis and its clinical surveillance. Neth J Med 1993;42:105-8.

62. Bulow S, Bulow C, Nielsen TF, Karlsen L, Moesgaard F Centralized registration, prophylactic examination, and treatment results in improved prognosis in familial adenomatous polyposis. Results from the Danish Polyposis Register. Scand J Gastroenterol 1995;30:989-93.

63. Herrera L, Kakati S, Gibas L, Pietrzak E, Sandberg AA. Gardner syndrome in a man with an interstitial deletion of $5 \mathrm{q}$. Am J Med Genet 1986;25:473-6.

64. Bodmer WF, Bailey CJ, Bodmer J, et al. Localization of the gene for familial adenomatous polyposis on chromosome 5 . Nature 1987;328:614-6.

65. Leppert M, Dobbs M, Scambler P, et al. The gene for familial polyposis coli maps to the long arm of chromosome 5 . Science 1987;238:1411-3

66. Powell SM, Petersen GM, Krush AJ, et al. Molecular diagnosis of familial adenomatous polyposis. N Engl J Med 1993;329:1982-7.

67. Bapat B, Noorani H, Cohen Z, et al. Cost comparison of predictive genetic testing versus conventional clinical screening for familial adenomatous polyposis. Gut 1999;44:698-703.

68. Moore J, Cowled P. Hereditary non-polyposis colorectal cancer syndrome. Aust N Z J Surg 1999;69:6-13.

69. Mecklin JP. Frequency of hereditary colorectal carcinoma. Gastroenterology 1987;93:1021-5. 
70. Evans DG, Walsh S, Jeacock J, et al. Incidence of hereditary non-polyposis colorectal cancer in a population-based study of 1137 consecutive cases of colorectal cancer. Br J Surg 1997;84:1281-5.

71. Aaltonen LA, Salovaara R, Kristo P, et al. Incidence of hereditary nonpolyposis colorectal cancer and the feasibility of molecular screening for the disease. N Engl J Med 1998;338:1481-7.

72. Ponz DL, Sassatelli R, Benatti P, Roncucci L. Identification of hereditary nonpolyposis colorectal cancer in the general population. The 6-year experience of a population-based registry. Cancer 1993; $71: 3493-501$

73. Aarnio M, Mecklin JP, Aaltonen LA, Nystrom-Lahti M, Jarvinen HJ. Life-time risk of different cancers in hereditary nonpolyposis colorectal cancer (HNPCC) syndrome. Int J Cancer 1995;64:430-3.

74. Vasen HF, Watson P, Mecklin JP, Lynch HT. New clinical criteria for hereditary nonpolyposis colorectal cancer (HNPCC, Lynch syndrome) proposed by the International Collaborative group on HNPCC. Gastroenterology 1999;116:1453-6.

75. Wijnen J, Khan PM, Vasen H, et al. Hereditary nonpolyposis colorectal cancer families not complying with the Amsterdam criteria show extremely low frequency of mismatch-repair-gene mutations. Am J Hum Genet 1997;61:329-35.

76. Burke W, Petersen G, Lynch P, et al. Recommendations for follow-up care of individuals with an inherited predisposition to cancer. I. Hereditary nonpolyposis colon cancer. Cancer Genetics Studies Consortium. JAMA 1997;277:915-9.

77. Vasen HF, Taal BG, Griffioen G, et al. Clinical heterogeneity of familial colorectal cancer and its influence on screening protocols. Gut 1994;35:1262-6.

78. Jarvinen HJ, Aarnio M, Mustonen H, et al. Controlled 15 year trial on screening for colorectal cancer in families with HNPCC. Gastroenterology 2000;118:829-34.

79. Lanspa SJ, Jenkins JX, Cavalieri RJ, et al. Surveillance in Lynch syndrome: how aggressive? Am J Gastroenterol 1994;89:1978-80.

80. Vasen HF, van Ballegooijen M, Buskens E, et al. A cost-effectiveness analysis of colorectal screening of hereditary nonpolyposis colorectal carcinoma gene carriers. Cancer 1998;82:1632-7.

81. Fuchs CS, Giovannucci EL, Colditz GA, Hunter DJ, Speizer FE, Willett WC. A prospective study of family history and the risk of colorectal cancer. N Engl J Med 1994;331:1669-74.

82. Winawer SJ, Zauber AG, Gerdes H, et al. Risk of colorectal cancer in the families of patients with adenomatous polyps. National Polyp Study Workgroup. N Engl J Med 1996;334:82-7.

83. Ahsan H, Neugut AI, Garbowski GC, et al. Family history of colorectal adenomatous polyps and increased risk for colorectal cancer. Ann Intern Med 1998;128:900-5.

84. St John DJ, McDermott FT, Hopper JL, Debney EA, Johnson WR, Hughes ES. Cancer risk in relatives of patients with common colorectal cancer. Ann Intern Med 1993;118:785-90.

85. Rozen P, Fireman Z, Figer A, Legum C, Ron E, Lynch HT. Family history of colorectal cancer as a marker of potential malignancy within a screening program. Cancer 1987;60:248-54.

86. Sackett DL. Bias in analytic research. J Chronic Dis 1979;32:51-63.

87. Pariente A, Milan C, Lafon J, Faivre J. Colonoscopic screening in first-degree relatives of patients with 'sporadic' colorectal cancer: a case-control study. The Association Nationale des Gastroenterologues des Hopitaux and Registre Bourguignon des Cancers Digestifs (INSERM CRI 9505). Gastroenterology 1998;115:7-12.

88. Guillem JG, Forde KA, Treat MR, Neugut AI, O’Toole KM, Diamond BE. Colonoscopic screening for neoplasms in asymptomatic first-degree relatives of colon cancer patients. A controlled, prospective study. Dis Colon Rectum 1992;35:523-9.

89. Sauar J, Hausken T, Hoff G, Bjorkheim A, Foerster A, Mowinckel P. Colonoscopic screening examination of relatives of patients with colorectal cancer. I. A comparison with an endoscopically screened normal population. Scand J Gastroenterol 1992;27:661-6.

90. Pignone M, Campbell MK, Carr C, Phillips C. Meta-analysis of dietary restriction during fecal occult blood testing. Eff Clin Pract 2001;4:150-6.

91. Ontario Expert Panel on Colorectal Cancer. Draft report of the Ontario Expert Panel on Colorectal Cancer. Toronto: Ontario Cancer Care, 1999.

92. Winawer SJ, Fletcher RH, Miller L, et al. Colorectal cancer screening: clinical guidelines and rationale. Gastroenterology 1997;112:594-642.

93. Hill M, Faivre J, Giacosa A. Preventative policies: A global perspective. In: GP Young, Prozen BL, eds. Prevention and Early Detection of Colorectal Cancer. London: WB Saunders, 1996.

94. Recommendations on Population on Screening for Colorectal Cancer in New Zealand. National Health Committee working Party on Population Screening for Colorectal Cancer. Aust NZ J Med 1999;112:4-6.

95. Fenlon HM, Nunes DP, Schroy PC, Barish MA, Clarke PD, Ferrucci JT. A comparison of virtual and conventional colonoscopy for the detection of colorectal polyps. N Engl J Med 1999;341:1496-503.

96. Sonnenberg A, Delco F, Inadomi JM. Cost effectiveness of colonoscopy in screening for colorectal cancer. Ann Intern Med 2000;133:573-84. 


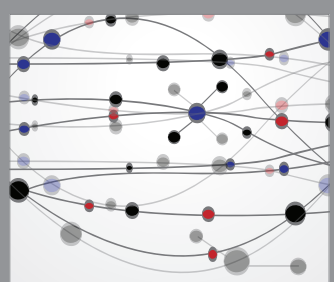

The Scientific World Journal
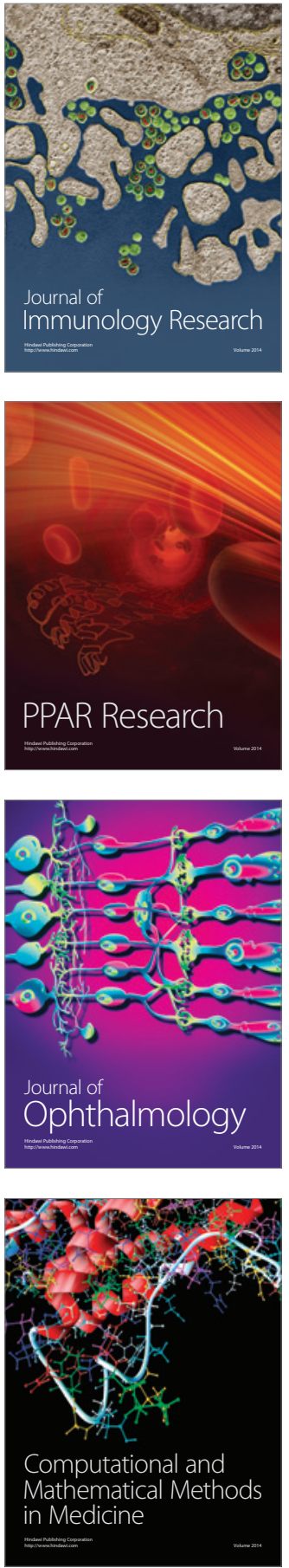

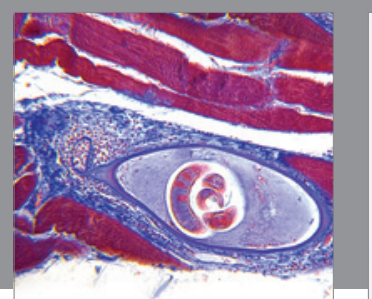

Gastroenterology Research and Practice

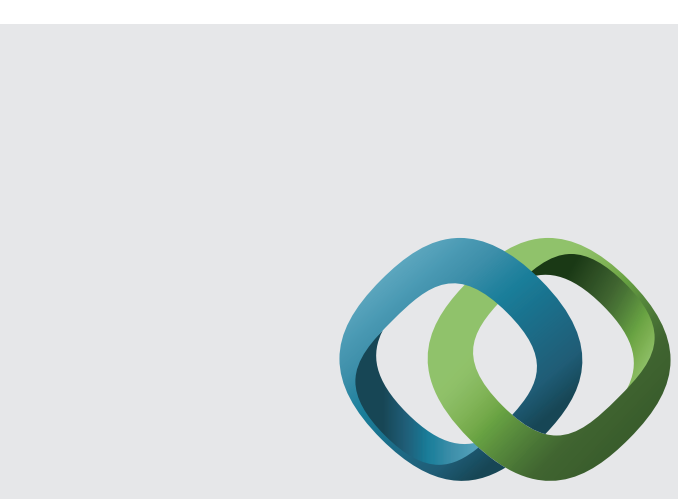

\section{Hindawi}

Submit your manuscripts at

http://www.hindawi.com
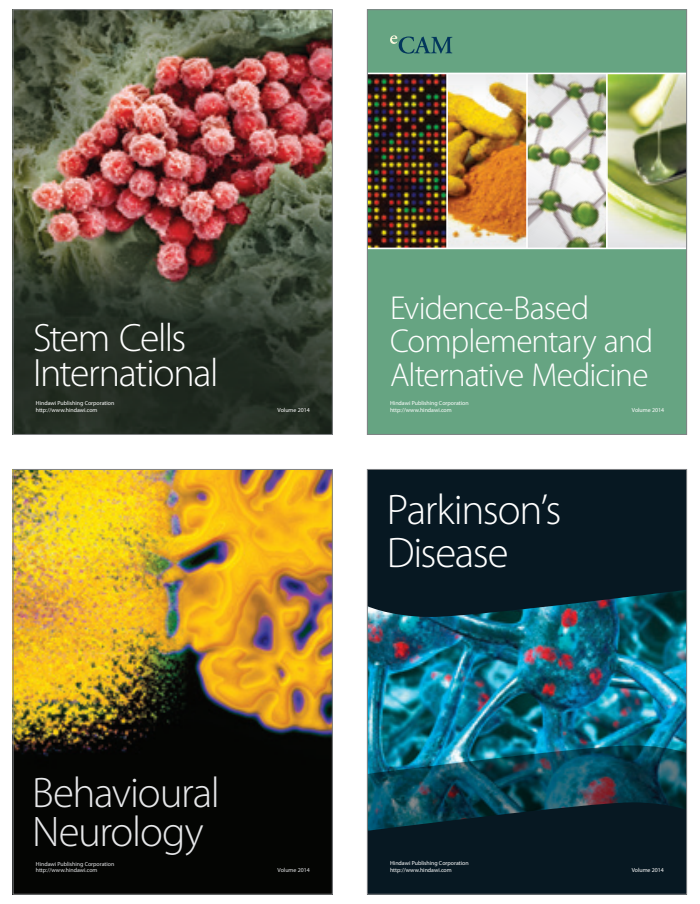
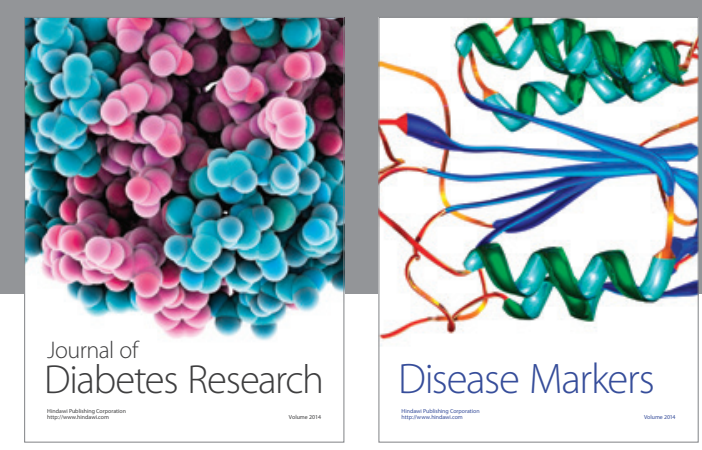

Disease Markers
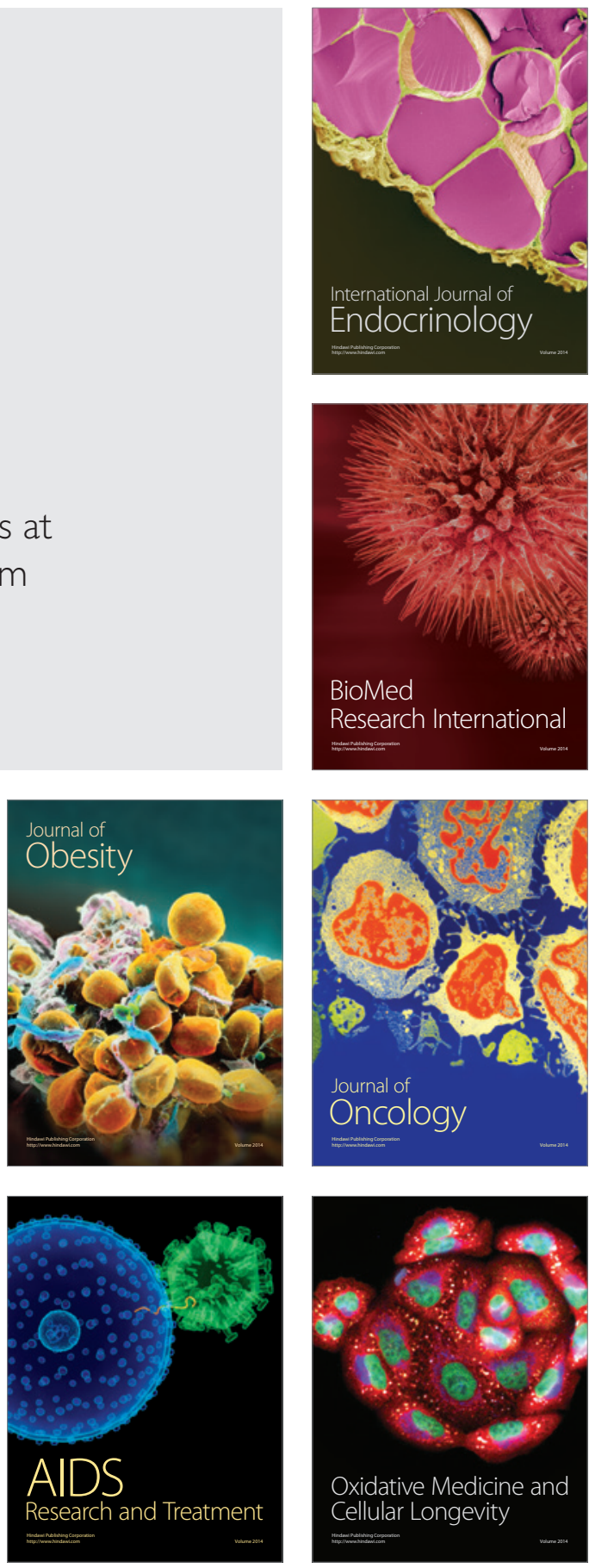